\title{
Modifikasi Sifat Mineralogi dan Fisiko-Kimia Bahan Tanah Vertik dengan Ball Mill Berenergi Tinggi
}

\section{Modifying the Mineralogical and Physico-Chemical Properties of Vertic-Soil Material by Using High-Energy Ball Milling}

\author{
Joko Priyono* , Ismail Yasin, Bustan \\ Program Studi Ilmu Tanah, Fakultas Pertanian, Universitas Mataram \\ *Corresponding Author Email: joko_priyono@unram.ac.id
}

Manuscript received: 08-12-2020. Accepted: 05-04-2021

\begin{abstract}
ABSTRAK
Uji coba modifikasi sifat bahan tanah vertik menggunakan teknik penggilingan dengan ball mill telah dilakukan tujuan utama untuk menghilangkan sifat vertik (mengembang-mengkerut) dan meningkatkan muatan partikelnya. Fraksi klei (clay) dari Vertisol Praya (Kabupaten Lombok Tengah) dikeringkan, kemudian digiling dengan ball mill selama 5, 10, dan 20 menit. Hasil penelitian menunjukkan bahwa fraksi klei tanah tersebut didominasi oleh mineral montmorillonit, dan penggilingan selama $\geq 5$ menit mengubah mineral kristalin montmorillonit menjadi partikel amorfus (non kristalin). Perubahan sifat itu diikuti dengan meningkatnya sifat vertik (mengembangmengkerut), kapasitas tukar kation, kapasitas menahan air, dan efek suspensi bahan tersebut. Peningatan reaktivitas (muatan elektrik) bahan menyebabkan jerapan air yang meningkat, sehingga sifat vertik bertambah. Disimpulkan bahwa tehnik high-energy ball milling efektif meningkatkan reaktivitas (muatan elektrik) tetapi juga sifat vertik bahan Vertisol. Diperlukan kajian lebih lanjut untuk mengevaluasi potensi multi-guna bahan vertik termodifikasi (partikel sangat reaktif) tersebut sebagai bahan baku industri keramik, campuran semen, penjerap logam berat dan senyawa kontaminan lainnya, maupun katalisator.
\end{abstract}

Kata kunci: ball milling; COLE; clay; montmorillonite; vertic

\begin{abstract}
Atest of modifying the properties of vertic material by using a ball milling technique was carried out with the primary aim to eliminate the vertic (swelling-shrinking) property and increase the electrical charge of the material. The clay fraction of Vertisol was dried and ball milled for 5, 10, and 20 minutes. Results reveal that the clay fraction of the soil material was dominated by montmorillonite mineral, and ball milling for $\geq 5$ minutes transformed the crystalline montmorillonite into amorphous (non-crystalline) particles. Those changes were followed by increasing the vertic features, cation exchange capacity, water holding capacity, and suspension effect of the milled material. The improvement of vertic characteristics might be due to the increase of electric charge of the milled particles. Thus, high-energy ball milling was an effective technique to improve the reactivity and
\end{abstract}


vertic property of vertic material of Vertisols. Further studies are needed to evaluate the potential uses of modified vertic materials as ceramic material, cement component, adsorbent of heavy metals, and other contaminants, or catalysator.

Keyword: ball milling; COLE; clay; montmorillonite; vertic

\section{PENDAHULUAN}

Salah satu sumberdaya alam yang melimpah di Pulau Lombok adalah tanah yang termasuk ordo Vertisol. Jenis tanah tersebutcukup luas di wilayah Kabupaten Lombok Tengah bagian selatan (Priyono et al., 2018). Vertisolsmempunyai sifat vertik (mudah mengembang-mengkerut). Dalam kondisi kering (musim kemarau), konsistensi tanah itu sangat keras disertai denganretakan lebar dan dalam sehingga tanah tersebut sulit diolah (sifat olahnya sangat berat); sedangkan pada kondisi basah (musim hujan),tanah itu sangat licin, plastis, mengembang hingga terbentuk gilgey (gundukan kecil)(Soil Survey Staff, 2014). Sifat tersebut menimbulkan banyak masalah dalam penggunaannya untuk lahan pertanian maupun non-pertanian, misalnya sebagai badan jalan atau pondasi konstruksi gedung dan jembatan. Intensitas sifat vertik tersebut ditentukan oleh kadar mineral liat 2:1 montmorillonit yang tinggi. Untuk memperluas kegunaannya, terutama dalam bidang non pertanian, sifat vertik mungkin perlu dihilangkanatau reaktivitas partikel klei (clay)-nya ditingkatkan.

Peran penting dari mineral montmorillonit dalam menentukan sifat vertik berkaitan dengan struktur kristalnya yang terdiri atas 2 struktur dasar tetrahedral Si mengapit oktahedral $\mathrm{Al}$; ruang antar dua kisi kristal tersebut dihubungkan oleh kation $\mathrm{Ca}^{+2}$ atau/dan $\mathrm{Mg}^{+2}$ yang bersifat mudah tertukarkan (Bohn et al., 2085). Keberadaan kation divalent sebagai penghubung antar kisi kristal mintmorillonit tersebut memegang peranan penting kaitannya dengan sifat vertik. Oleh karena itu, untuk meningkatkanmulti-guna dari material vertik yang keterse-diaannya melimpah tersebut, maka perlu dimodifikasi struktur kristalnya, terutama pada mineral 2:1 montmorilonit. Tujuan modifikasi itu adalah untuk menghilangkan sifat vertik, atau sekaligus meningkatkan reaktivitas partikel tersebut.

Dari aspek teknologi, penggilingan intensif dengan ball mill (nano technology) banyak diterapkan dengan berbagai tujuan, khususnya memodifikasi sifat material logam atau mineral. Misalnya, teknik tersebut digunakan oleh para pakar di bidang keramik, antara lain referensi (Gasalla et al., 1987)pada mineral $\alpha$-spodomene dan (Garcia et al., 1991) pada mineral kaolins. Ball milling juga digunakan untuk pengembangan bahan penjerap kontaminan acid drainage mining(Prastistho et al., 2018). Teknologi tersebut merupakan salah satu alternatif untuk ekploitasi partikel mineral liat, untuk menyiapkan PCN yang tidak dapat diproses secara konvensional(Ramadan et al., 2010).

Penerapan teknologi nato pada bidang pertanian antara lain untuk memproses mineral silikat (Harley, 2002), batuan silikat (Priyono, 2005), batuan fosfat (Lim et al., 2003; Priyono, 2008) menjadi pupuk, dan (Aglietti, 1994) mensintesis mineral. Hasil dari berbagai penelitian tersebut menujukkan bahwa penggilingan dengan ball millmerusak struktur kristal, mengurangi ukuran partikel dan meningkatkan luas permukaan efektifnya. Peneliti (Onweremadu dan Anikwe, 2007)melaporkan bahwa penggilingan dalam kondisi kering pada mineral talc meningkatkan kapasitas tukar kation (KTK) dan Mg terlarut dalam air. Namun, 
jikapenggilingan terlalu intensif justru dapat memperbesar ukuran partikel dan menghambat ketersediaan unsur hara dari bahan batuan tersebut karena terjadinya aglomerasi ataupun sintering. Oleh karena itu, intensitas penggilingan yang optimal untuk masing-masing jenis bahan perlu diidentifikasi (Priyono, 2005).

Terkait dengan upaya memodifikasi sifat bahan tanah vertik, khususnya untuk material Vertisols dari P. Lombok, dengan tujuan untuk meningkatkan multi-guna bahan tanah itu dalam bidang pertanian, teknik, atau industri keramik (gerabah) belum pernah dilakukan.Pertanyaan yang belum terjawab, apakah ball millingefektif digunakan untuk tujuan tersebut dan seberapa intensif harus diterapkan? Oleh karena itu perlu kajian modifikasi material vertik menggunakan ball mill dengan harapan bahwa teknologi tersebut dapat dijadikan sebagai cara mudahdan efektif untuk meningkatkan multi-guna sumberdaya alam melimpah itu untuk berbagai bidang.

Peper ini menyajikan hasil kajian awalmengenai modifikasi sifat mineralogi dan beberapa fisiko-kimia bahan tanah vertik menggunakan teknik penggilingan dengan ball mill.

\section{Bahan Penelitian}

\section{BAHAN DAN METODE}

Bongkahan sample tanah vertik (Vertisols) diambil dari Lombok Tengah (di dekat Bendungan Batujahe) pada kedalaman $0-15 \mathrm{~cm}$, dibersihkan dari kotoran/bahan organik dan sisa akar tanaman. Selajutnya, bongkah tanah tersebut dipecahkan dengan palu hingga diperoleh agregat tanah berdiameter $<1 \mathrm{~cm}$. Contoh tanah vertik dilarutkan ke dalam air, diaduk hingga membentuk suspensi, kemudian didiamkan sekitar dua jam. Larutan suspensi dipisahkan (disaring) untuk memisahkan partikel klei dengan pasir dan debu, serta partikel kasar yang melayang (bahan organik). Suspensi partikel clay dikeringkan di bawah terik matahari hingga betul-betul kering.

\section{Penggilingan}

Proses penggilingan partikel tanah dilakukan di Pabrik Pupuk PT. JIA Agro Indonesia (di Desa Akar-Akar, Kabupaten Lombok Utara) menggunakan mesin ball mill horizontal. Parameter ball milling: diameter tabung ball millbagian dalam adalah $48 \mathrm{~cm}$, dan panjang $120 \mathrm{~cm}$; diameter bola baja yang digunakan adalah $17 \mathrm{~mm}$ (440C-stailess steel ball), rasio $(\mathrm{w} / \mathrm{w})$ bola baja : partikel yang digiling $=2: 1(10 \mathrm{~kg}$ bola baja, $5 \mathrm{~kg}$ sampel partikel yang digiling), dan kecepatan putar mesin 80 - $90 \mathrm{rpm}$. Proses penggilingan dilakukan selama 5, 10, dan 20 menit.

\section{Analysis Sifat Material}

Setelah proses penggilingan, material yang dihasilkan dianalisis untuk mengidentifikasi sifat mineralogi, COLE (coefficient of linear extensibility), kapasitas tukar kation, kapasitas memegan air, dan efek suspensi masing-masing material yang sudah digiling dengan waktu penggilingan yang berbeda ( 0 (kontrol), 5, 10, dan 20 menit) sebagai berikut:

1). Jenis dan sifat mineralogi material diidentifkasi melalui analisis difraksi sinar $\mathrm{x}$ ( $x$-ray diffraction - XRD), dilakukan di Laboratorium Hidrogeologi dan Hidrokimia, ITB - 
Bandung. Mesin yang digunakan adalah Rigaku SmartLab X-Ray Diffractometer menggunakan tabung (tube) sumber sinar $\mathrm{x}$ dari $\mathrm{Cu}-\mathrm{K \alpha}(\lambda=1.5054 \mathrm{~nm})$, sudut pembacaan $2 \theta$ pada $2-30$ derajad, interval pembacaan 0,02 derajad, 5 reading/sec.

2). COLE (coefficient of linear extensibility), ditentukan berdasarkan nilai bobot jenis volume pada kondisi jenuh air atau retensi sekitar $1 / 3$ bar $\left(\mathrm{BJV}_{1 / 3}\right.$ bar $)$ dan kering oven $\left(\mathrm{BJV}_{\mathrm{ov}}\right)$ dari masing-masting material sesuai dengan perlakuan waktu penggilingan.

Nilai COLE $=\left(\mathrm{BJb}_{1 / 3} \text { bar } / \mathrm{BJV}_{\mathrm{ov}}\right)^{1 / 3}-1$.

3). Kapasitas tukar kation (KTK), diukur dengan larutan penukar kation $\mathrm{NH}_{4} \mathrm{OAct} \mathrm{pH} 7,0$. Kuantitas kation penukar $\left(\mathrm{NH}_{4}{ }^{+}\right)$diukur melalui destilasi.

4). Effect suspensi (ES), diukur dengan $\mathrm{pH}$ meter, yaitu selisih nilai $\mathrm{pH}$ yang diukur pada suspensi tetelah partikel diendapkan (larutan jernih) dengan nilai $\mathrm{pH}$ yang diukur pada larutan suspensi keruh; rasio partikel: $\mathrm{H}_{2} \mathrm{O}=1: 5$.

\section{Sifat Mineralogi Material}

\section{HASIL DAN PEMBAHASAN}

Pada pola XRD (Gambar 1), peak untuk jenis mineral yang lain selain montmorillonit (peak pada $2 \theta$ sekitar 6 derajad) tidak tampak dengan jelas. Artinya, $>90 \%$ fraksi klei pada Vertisol Praya adalah montmorillonit. Informasi tingkat kemurnian komposisi mineralogi klei ini sangat penting kaitannya dengan peluang penggunaan fraksi klei Vertisol Praya sebagai standar (referensi) dalam identifikasi mineral. Lembih lanjut, $d$-spacing fraksi klei yang tidak digiling (kontrol) adalah $15,71 \AA$, dan sedikit berkurang akibat penggilingan menjadi $1,46 \AA$ (pengilingan selama 20 menit).

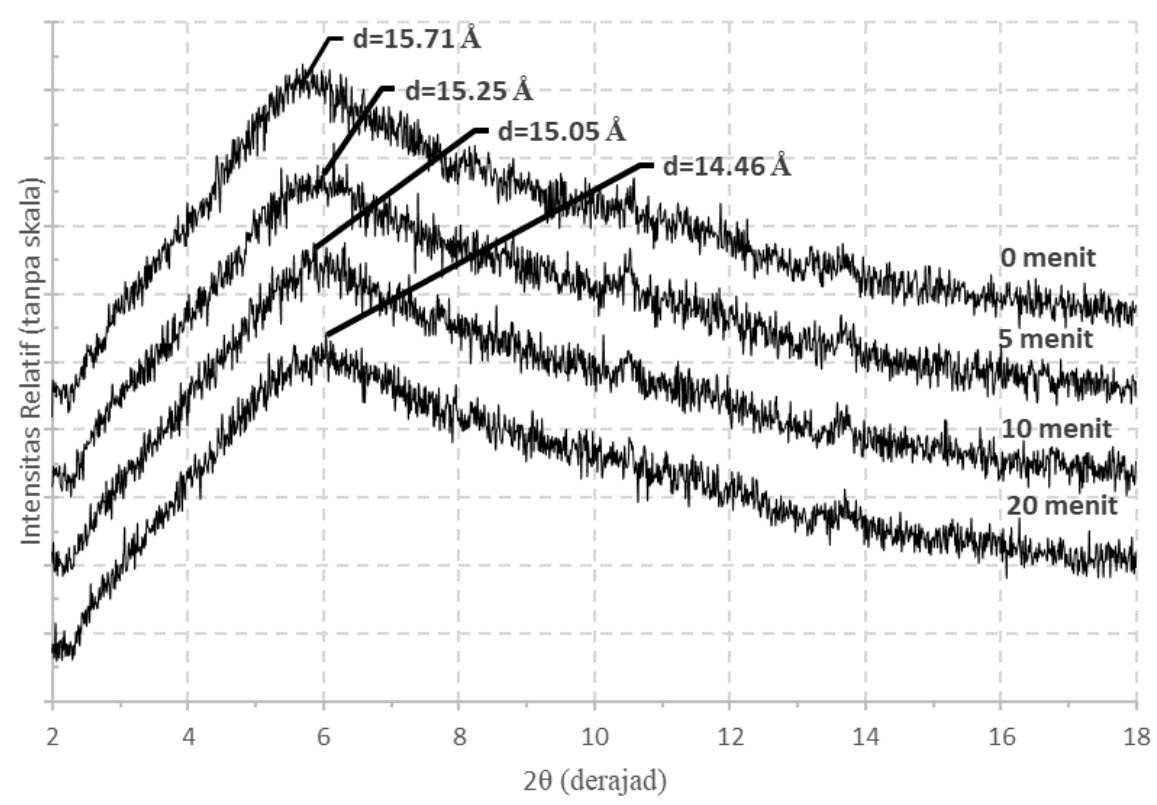

Gambar 1. Difraksi sinar x (XRD peaks) bidang kristal [100] mineral montmorillonit dari fraksi klei Vertisol Praya yang digiling dengan ball mill selama 0, 5, 10, dan 20 menit. 
Pada Gambar 1 tampak bahwa penggilingan dengan ball mill selama 5, 10, dan 20 menit menurunkan kristalinitas struktur montmorillonit, ditandai dengan XRD peaks $2 \theta$ sekitar 6 derajad yang sidikit makin melebar. Artinya, bidang kristal mineral montmorillonit pada material yang digiling tersebut telah mengalami sedikit kerusak struktur kristalnya, sehingga difraksi sinar x makin melebar karena meningkatnya noice difraksi sinar $\mathrm{x}$, dan sudut puncak difraksi (sudut 2 $\theta$ ) makin besar, atau $d$-spacing makin mengecil .

Terjadinya penurunan kristalinitas (amorfisasi) mineral akibat penggilingan dengan ball mill seperti ditunjukan pada Gambar 1, mirif dengan yang ditujukan oleh peneliti sebelumnya pada mineral sekunder (Gasalla et al., 1987; Garcia et al., 1991; Aglietti, 1994; Ramadanet al., 2010) maupun pada mineral primer(Harley, 2002) atau batuan (Priyono, 2005; 2008; Lim et al., 2002) yang intensitas penggilingannya sangat intensif (beberapa jam). Benturan oleh bola baja dengan kecepatan dan frekuensi tinggi menyebabkan kerusakan setidaknya pada struktur polihedral klei yang digiling, dan memperhalus ukuran partikel menjadi berukuran nanometer (nano particles). Pada penelitian ini, penggilingan sampai dengan 20 menit belum menggidikasikan terjadinya anglomerasion atau sinteringdimana ukuran partikel bahan makin kasar (disebabkan oleh intestitas penggilingan yang terlalu tinggi). Oleh karena itu, untuk mendapatkan hasil modifikasi yang optimum atau reaktivitas material yang maksimum, intensitas penggilingan bahan vertik tersebut masih dapat ditingkatkan sampai mencapai batas penggilingan optimum. Perlakuan itu dapat diterapkan melalui peningkatan kecepatan giling, rasio bahan : bola baja, ataupun durasi penggilingan secara bertahap.

\section{Sifat Fisik dan Kimia Material}

Nilai rerata COLE (coefficient of linear extensibility), kapasitas tukar kation (KTK), kapasitas menahan air (KMA), dan efek suspensi (ES) pada intensitas penggilingan $0-20$ menit disajikan pada Tabel 1. Data pada Tabel 1 menunjukan bahwa penggilingan dengan ball mill selama 0 - 20 menit meningkatkan semua nilai parameter sifat fisik dan kimia (COLE, KTK, MKA, dan ES) bahan tanah vertik yang dikaji dalam penelitian ini.

Tabel 1. Nilai (rerata + simpangan baku) coefficient of extensibility (COLE), kapasitas tukar kation (KTK), kapasitas menahan air (KMA), dan efek suspensi (ES) material yang digiling dengan ball mill selama $0-20$ menit

\begin{tabular}{ccccc}
\hline $\begin{array}{c}\text { Penggilingan } \\
\text { (menit) }\end{array}$ & COLE & $\begin{array}{c}\text { KTK } \\
\left(\mathrm{Cmol}_{\mathrm{c} \cdot \mathrm{kg}^{-}}\right)\end{array}$ & $\begin{array}{c}\text { KMA } \\
(\%)\end{array}$ & $\begin{array}{c}\text { ES (1:5) } \\
\text { (unit pH) }\end{array}$ \\
\hline 0 & $0,273 \pm 0,021$ & $132,6 \pm 8,2$ & $93,4 \pm 4,9$ & $0,24 \pm 0,03$ \\
5 & $0,338 \pm 0,016$ & $172,3 \pm 12,1$ & $119,5 \pm 6,9$ & $0,41 \pm 0.06$ \\
10 & $0,404 \pm 0,042$ & $175,8 \pm 9,8$ & $133,9 \pm 7,2$ & $0,42 \pm 0.05$ \\
20 & $0,435 \pm 0,052$ & $226,2 \pm 11,2$ & $146,0 \pm 5,3$ & $0,48 \pm 0.04$ \\
\hline
\end{tabular}

Keterangan: pengukuran dilakukan 5 kali (ulangan) dari sample yang diambil secara acak

Batas minimal nilai COLE suatu material tanah dikategorikan sebagai bahan vertik dan bersifat bahaya/dapat merusak pondasi bangunan adalah 0,06 (Onweremadu dan Anikwe, 2007), atau berkorelasi positif dengan kadar clay(Vaught, 2006). MenurutSoil Survey Staff 
(1972), nilai COLE $\geq 0,09$ dianggap bersifat vertik yang potensial, sedangkan menurut Grossmanet al.(1968), nilai COLE $\geq 0,03$ mengindikasikan dominasi mineral montmorillonit pada bahan tanah tersebut. Berdasarkan hasil penelitian sebelumnya (Priyono et al., 2018), kadar clay Vertisol Praya sekitar $56 \%$, sehingga sifat vertik (COLE) tanah tersebut seperti terlihat pada Tabel 1 sangat nyata dan berbahaya/potensial merusak pondasi bangunan.

Peningkatan nilai COLE akibat penggilingan kemungkinan berkaitan dengan meningkatnya kapasitasmenahan air (KMA), atau makin luasnya permukaan efektif material klei. Tingginya KMA(material yang digiling 5 - 20 menit) yang diakibatkan oleh luas permukaan efektif ternyata lebih tinggi daripada yang disebabkan oleh struktur kristalin montmorillonit yang tidak digiling (KMA kontrol). Hal tersebut merupakan penjelasan mengapa nilai COLE fraksi clayyang digiling bukannya turun (menghilangkan sifat vertik) tetapi justru meningkat (lebih vertik). Penjelasan tersebut didukung oleh pengamatan visual terjadinya retakan (pada kondisi kering oven 105o C) yang lebih intensif pada fraksi clay yang digiling dengan ball mill.

Meningkatnya nilai KTK, KMA, serta SE merupakan indikasi kuat bahwa penggilingan fraksi liat Vertisol dengan ball mill meningkatkan reaktivitas partikel atau bahan vertik tersebut. Informasi tentang meningkatnya reaktivitas material tanah akibat penggilingan itu sangat penting kaitannya dengan upaya memperluas pemanfaatan sumberdaya alam berupa bahan tanah vertik dalam berbagai bidang industri, antara lain industri keramik, bahan perekat, penyaring limbah, atau bahan camppuran semen dan katalis.

\section{KESIMPULAN}

Penggilingan bahan tanah vertik (fraksi clay dari Vertisol) dengan ball mill selama 5 - 20 menit merubah mineral clay montmorillonit yang kristalin mejadi bahan yang bersifat amorfus. Perubahan sifat mineralogi tersebut berdampak pada peningkatan nilai coefficient of linear extensibility (COLE) dan reaktivitas material yang diindikasikan oleh peningkatan kapasitas tukar kation (KTK), kapasitas menahan air (KMA), dan efek suspensi (ES). Untuk mengetahi kemungkinan bertambahnya multi guna dari sumberdaya alam bahan vertik tersebut untuk kegunaan dalam beragam bidang industri diperlukan kajian lebih lanjut.

\section{Ucapan Terima Kasih}

Ucapan terimakasih disampikan kepada pihak LPPM Universitas Mataram yang telah membantu pembiayaan kegiatan riset ini melalui anggaran PNBP 2020.

\section{DAFTAR PUSTAKA}

Aglietti, E.F. 1994. The effects of dry grinding on the structure of talc. App. Clay Sci. 9: 4 147.

Bohn, H., B. McNeal, G. O'Connor. 1985. Soil chemistry. $2^{\text {nd }}$ Edition, Wiley-Interscience, Chichester.

Gasalla, H.J., E.F. Anglietti, J.M. Lopez, R. Pereira. 1987. Change in physicochemical properties of $\alpha$-spodumene by mechanochemical treatment. Material Chem. Phys. 17: $379-389$. 
Garcia, F.G., M.T.R. Abrio, M.G. Rodziguez. 1991. Effects of dry grinding on two kaolins of different degree of crystallinity. Clay Min. 26: 549 - 565.

Grossman R. B., B.R. Brasher, D.P. Franzmeier, J.L. Walker. 1968. Linear extensibility as calculated from natural-clod bulk density measurements. Soil Sci. Soc. Am. Proc. 32:570-573.

Harley, A.D. 2002. Evaluation and improvement of silicate mineral fertilizers. (Ph.D thesis: The University of Western Australia).

Lim, H.H., R.J. Gilkes, P. McCormick. 2003. Beneficiation of rock phosphate fertilizers by mechano-milling. Nutrient Cycling in Agroecosystems67:177 - 186.

Onweremadu, E.U. \& Anikwe, M.A.N., 2007. Homomorphic modelling of shringkage properties of soils of southereastern Nigeria for sustainable land use. Int. J. Soil Sci. 2(4): $286-293$.

Prastistho, W., W. Kurniawan, H. Honode. 2018. Passive remediation of acid mine drainage using ball-milling modified Indonesian natural bentonite: laboratory barch and column sorption of manganese. Green Sust. Chem. 8: 295-310.

Priyono, J., I. Yasin, M. Dhlan, Bustan. 2018. Identifikasi sifat, ciri, dan jenis tanah utama di Pulau Lombok. J. Sains Teknologi \& Lingkungan 5(1): 19 - 24.

Priyono, J.2005. Effects of high energy milling on the performance of silicate rock fertilizers. (Ph.D. Thesis, The University of Western Australia).

Priyono, J. 2008. Effect of ball milling under various conditions on several physicochemical properties of rock phosphate fertilizer. J. Tanah dan Iklim1: $1-8$.

Ramadan, A.R., Esawi, A.M.K. \& Gawad, A.A., 2010. Effect of ball milling on the structure of $\mathrm{Na}^{+}$-montmorillonite and organo-montmorillonite (cloisite 30B). Applied Clay Sci. 47: $196-202$.

Soil Survey Staff. 1972. Soil taxonomy: abasic system of soil classification for making and interpreting soil surveys. Soil Conservation Service, Agriculture Handbook No. 436.

Soil Survey Staff. 2014. The keys to soil taxonomy. $12^{\text {th }}$ Edition, USDA-NSCR, Wisconsin, USA. p. 39.

Vaught, R., K.R. Brye, D.M. Miller. 2006. Relationships among coefficient of linear extensibility and clay fractions in expansive, stoney soils. Soil Sci.Soc.Am. J.70: 1983 -1990 . 